\title{
THE FOURTH WORLD COMPUTER CHESS CHAMPIONSHIP
}

The Association for Computing Machinery (ACM) is the principal sponsor of the Fourth World Computer Chess Championship, which will be held in New York, U.S.A., from October 22 to October 25. This tournament will encompass the annual well-known ACM tournament; at least the name is changed for this year. In fact it will be the fourteenth time that the ACM organizes a computer chess tournament. The tournament will take place in the Sheraton Centre in New York. The programs play a five-round Swiss style tournament; the first round of play is scheduled on Saturday, October 22, 1983, at 7:30 $\mathrm{p} \cdot \mathrm{m}$.

\section{THE TITLE WORLD CHAMPION}

The programs will compete for the title of 'World Computer Chess Champion 1983'. So far, three championships have been held with the following resu1ts:

Stockholm 1974 KAISSA

Toronto 1977 CHESS 4.6

Linz 1980 BELLE
(V.L. Arlazarov, G.M. Adelson-Velsky, A.R. Bitman \& M.V. Donskoy)

(L.R. Atkin \& D.J. Slate)

(K. Thompson \& J. Condon)

THE ORGANIZATION

The tournament organizing committee consists of: M. Newborn, B. Mittman, T.A. Marsland, K. Thompson, K. Spracklen, D. Levy, R. Hyatt. The committee which determines the admission of programs to the tournament contains two USA members ( $K$. Thompson \& R. Hyatt) and two European members (P.J. van Diepen (The Netherlands) \& M. Engelbach (West Germany)).

\section{THE PARTICIPANTS}

At the closing date for entries, August 2, 1983, 26 programs have applied for participation. At the deadline of this issue of the Journal, the committee had not decided among the entries. The applying programs were: Belle, Advance 3.0, Schach 2.7, Merlin, Cray Blitz, Sfinks, Pion, Ostrich, Bebe, BCP, AWIT, Rapier, GVNAF, Philidor 2, PK 83, Novag Experimental, Patsoc, Nuchess, Chess Challenger, Chaos, Kaissa, Phoenix, Shy, Bobby, Conchess, Chess D. 